\title{
Prevalence and Risk of Pulmonary Hypertension in Chronic Kidney Disease
}

\author{
Ali Abdul Majid Dyab Allawi ${ }^{1}$, Mohammed Hannon Alsodani², Ahmed Mushhin Hardan Alqaisi ${ }^{3}$ \\ ${ }^{1}$ FRCP London, Assistant Professor, Department of Internal Medicine, Baghdad College of Medicine \\ Consultant Nephrologist, Baghdad Teaching Hospital, Baghdad, Iraq \\ ${ }^{2}$ Consultant Nephrologist, Lecturer at Baghdad College of Medicine, Baghdad, Iraq \\ ${ }^{3}$ Internist and Specialist, Baghdad Teaching Hospital, Baghdad, Iraq
}

\begin{abstract}
Pulmonary hypertension is common in chronic kidney disease patients treated by hemodialysis ( 30\%). Objectives: The prevalence of Pulmonary hypertension in chronic kidney disease in Baghdad teaching hospital. Patients and methods: Study performed from April 2015 to April 2016, patients with valvular heart disease, pulmonary diseases with abnormal pulmonary function test were excluded, all patients did pulmonary function test before Doppler echo to avoid false positive results, About 80 patients, 40 with chronic kidney disease pre-dialysis 27 male and 13 female, and 40 treated by hemodialysis 22 male and 18 female from dialysis units and medical wards. Results and discussion: Mean age was $51.6 \pm 14.2$ in predialysis group, and $53.4 \pm 12.6$ in dialysis group (ranging from 20 to 70 years). Dialysed patients carry increasing risk for having Pulmonry hypertension $(O R=3)$ compare to predialysis. Anemia increase the risk for development of $\mathrm{PH}$ with an $\mathrm{OR}=3.42$. As the stage of chronic kidney disease increase the incidence of PH increase in which in stage $V$ it reach $15 \%$ compare to stage IV $3.75 \%$ and lower in the other stages. Patients with age above 50 represent $70.6 \%$ of $\mathrm{PH}$ patients, so age increase the prevalence of pulmonary hypertension.
\end{abstract}

Keywords: pulmonary hypertension, chronic kidney disease, predialysis, hemodialysis.

\section{Introduction}

The prevalence of $(\mathrm{PH})$, defined as Doppler-derived pulmonary artery systolic pressure (PASP) $>35 \mathrm{~mm} \mathrm{Hg}$, was $\sim 5 \%$. Most cases detected in Olmsted County were related to underlying left ventricular (LV) disorders: PASP was associated with both systemic hypertension and high pulse pressure and with diastolic dysfunction as measured by the $\mathrm{E} / \mathrm{e}^{\prime}$ ratio (early transmitral flow velocity $[\mathrm{E}]$ to early mitral annular tissue velocity [ $\left.\mathrm{e}^{\prime}\right]$ )[1]. In this diagnostic category, the prevalence of pulmonary artery hypertension related to background diseases is $7 \%-12 \%$ in systemic sclerosis [2][3], $2 \%-6 \%$ in portal hypertension, and $\sim 30 \%$ in congenital heart disease. $\mathrm{PH}$ is exceedingly prevalent $(15 \%-20 \%)$ in patients with sleep apnea (WHO diagnostic category III)[4].

Various PASP cutoffs have been applied, ranging from 25 to $\geq 45 \mathrm{~mm} \mathrm{Hg}$, and in one study, TRV $\geq 2.5 \mathrm{~m} / \mathrm{s}$ was adopted as the major criterion to make the diagnosis of $\mathrm{PH}$ [5][6][7].Hypertension and diabetes mellitus (DM), 2 dominant causes of kidney disease, trigger LV diastolic dysfunction, an alteration found to increase pulmonary venous and arterial pressure. Chronic volume overload, a factor implicated in LV disorders and in the high venous return in patients with $\mathrm{CKD}$, may induce pulmonary venous hypertension by both increasing pulmonary blood flow and adversely affecting LV function [8]. If sustained, vasoconstriction in the lung leads to extensive remodeling of the pulmonary vessels and a steady reduction in vessel compliance, a phenomenon which in and of itself contributes to pulmonary hypertension [9][10]. Well-performed studies show that pulmonary pressure increases with AVF creation [11] and that $\mathrm{PH}$ tends to worsen over time in these populations. Accordingly, in HD patients, AVF flow and
AVF duration are related independently to the severity of pulmonary hypertension. AVF compression by a sphygmomanometer or surgical AVF closure[12] induces a rapid decrease in mean cardiac output followed by a stable decrease in pulmonary pressure.

PH is higher with HD than PD. Exposure to dialysis membranes, Neutrophil activation Secondary to blooddialysis membrane contact accompanied by reversible neutrophil sequestration in the lung, a phenomenon that was intensively investigated in the 1980s, contributes to causing or worsening microvascular lung disease in HD patients [13].

The hypothesis that volume overload and LV disorders triggered or exacerbated by kidney disease and repeated exposure to dialysis membranes may cause $\mathrm{PH}$ independently of the AVF and other factors is supported by the demonstration that kidney transplantation may revert pulmonary artery pressure to normal in patients ho still have a functioning AVF[14]. Endothelial Dysfunction Endothelial dysfunction is a main trigger of $\mathrm{PH}$ in patients with $\mathrm{CKD}$, in whom endothelial dysfunction is prevalent [15]. The impaired capacity of the endothelium to regulate vascular tone in patients with CKD depends on an imbalance between vasoconstrictors (e.g., high levels of endothelin 1) and vasodilators (reduced generation of nitric oxide [NO])[16]. So, asymmetric dimethyl arginine (ADMA), an endogenous inhibitor of NO synthase that is synthesized widely at lung level and that accumulates in CKD , ADMA is a reasonable uremic toxin potentially implicated in $\mathrm{PH}$ in this population [17].Sleep apnea is a factor of great importance for the high risk of $\mathrm{PH}$ in the setting of CKD [18], and a close link between oxygen saturation and PAP has been established in clinical physiology experiments in both healthy persons and patients with chronic obstructive pulmonary disease. 


\section{International Journal of Science and Research (IJSR) \\ ISSN (Online): 2319-7064}

Index Copernicus Value (2015): 78.96 | Impact Factor (2015): 6.391

Sympathetic activation is the main mechanism whereby hypoxemia increases pulmonary pressure [19]. In this respect, it is interesting to note that patients with sleepdisordered breathing have increased ADMA levels[20]. Furthermore, circulating levels of this NO synthase inhibitor are associated with sympathetic nerve activity (as assessed by measurements in the peroneal nerve) in patients with CKD and with norepinephrine levels in dialysis patients [21, 22].

Severe anemia is an established cardiovascular risk factor in CKD and its impact on the cardiovascular system extends to pulmonary circulation because low hemoglobin levels can contribute to $\mathrm{PH}$ by aggravating hypoxia triggered by concomitant conditions [23].

\section{Patients and methods}

Patient selection :The original study population included 80 patients $50 \%$ (40 patients)treated by conservative treatment (control group) \& 50\%(40) treated by hemodialysis via AV fistula(HD group) in Baghdad teaching hospital from April 2015 to April 2016 several patients were excluded initially from study due to long term multiple comorbidities and long history of COPD, HF, \& valvular heart disease.vThis study take approval of ethical committee from Arab board department of medicine in Iraq. Informed patient consent according to Helsinki declaration were taken, also all patients selected in our study perform pulmonary function test to exclude respiratory problem and avoid false positive results and all them show accepted results that indicate proper selection of groups.

Patient evaluation: Systolic PASP was estimated in 80 patients by Doppler echocardiography. All patients in 2nd group (HD group) had a duration ranging from 3 to 6 months on HD which was sufficient time for pathophysiological changes to occur. To avoid overestimation of PAP due to volume overload, the echocardiography performed within few hours (between 2 to 5 hours) post session of HD while patient in dry weight after estimation of blood pressure and body weight. Doppler echocardiography was obtained for each patient. PASP was calculated using modified Bernoulli equation:

$\mathrm{PASP}=4$ (tricuspid regurgitation jet)2+(estimated right avtrial pressure).

Right a trial pressure measured by vena cava diameter \& degree of inspiratory collapse 7 .

Diagnostic criteria: $\mathrm{PH}$ mean $>25 \mathrm{mmHg}$ measured by right side catheterization in addition to pulmonary wedge pressure $<15 \mathrm{mmHg} \&$ pulmonary vascular resistance $>3$ woods unit.vNoninvasive measurement of $\mathrm{PH}$ can be done by Doppler echocardiography. In echo study measurement of PASP based on T.V. regurgitation jet with exclusion of other physiological \&pathological causes. Significant $\mathrm{PH}$ occur when PASP $>50 \mathrm{mmHg} \& /$ or $\mathrm{TVR}>3.4 \mathrm{~m} / \mathrm{s}$, but as grades of Severity classified to mild (below $45 \mathrm{mmHg}$ ), moderate (46mmHg-60 mmHg), severe(more than $60 \mathrm{mmHg}$ ). The machine used was Philips CX50, and views were apical 4 chambers, parasternal short axis\& RV inflow views. This echo study done by professional echo doctor from Baghdad teaching hospital. Echo study was done for 1st group on conservative treatment, and in dialysis unit by same machine for 2nd group on HD.

Statistical analysis: Data of all patients were entered and analyzed with the statistical package of social sciences (SPSS) version 21.Age and duration on HD were presented as mean \pm standard deviation (SD), other variables were presented as frequencies (numbers) and proportions (\%). Student's test was used to compare means. Chi square test was used to compare frequencies. Odds ratio (OR) was calculated to estimate the risk and the association of PHT with each of Anemia and viral screening findings. Level of significance ( $\mathrm{P}$ value) was set at 0.05 as cutoff point for significant difference or association. Results were presented in tables with an explanatory paragraph for each table by using Microsoft Office word software version 2010.

\section{Results}

There were 80 patients with CKD enrolled in this study, 40 of them $(50 \%)$ were on conservative treatment (pre dialysis group) and the other 40 patients on HD (HD group).The mean age of patients in pre dialysis group was $51.6 \pm 14.2$ years compared to $53.4 \pm 12.6$ years in HD group, with a range of $20-70$ years (table 1 ).

Table 1: General characteristics of patients

\begin{tabular}{|c|c|c|c|}
\hline Variable & Pre dialysisvgroup & HD Group & $P$ value \\
\hline \multicolumn{5}{|c|}{ Age } \\
\hline mean \pm SD & $51.6 \pm 14.2$ & $53.4 \pm 12.6$ & 0.34 \\
\hline Range & $20-70$ & $20-70$ & \\
\hline \multicolumn{5}{|c|}{ Duration on HD (months) } \\
\hline mean SD & -- & $4.1+1.3$ & - - \\
\hline Range & -- & $3-6$ & -- \\
\hline
\end{tabular}

DM was found in 13 patients $(32.5 \%)$ of pre dialysis group and 12 patients $(30 \%)$ in HD group and was of no statistical significance. Anemia was significantly more frequent in HD group than predialysis group, it was found in 11 pre dialysis patients $(27.5 \%)$ and $22(55 \%)$ of HD patients $(\mathrm{P}=0.021) .$. Hypertension reported in 10 predialysis patients (25\%) and $13(32.5 \%)$ of HD patients and was found of no statistical significance, other diseases were found to be less frequent distribution, no significant differences had been found in between studied groups regarding the hypertension, Chronic infection, stones, systemic lupus erythematosus (SLE) or polycystic kidney disease (PCKD), in all comparison at $\mathrm{P}>0.05$. Regarding $\mathrm{PHT}$ it was reported in 5 pre dialysis patients giving a prevalence of $12.5 \%$ among this group, and it was found in $12 \mathrm{HD}$ patients with a prevalence of $30 \%$, it had been significantly found PHT was more prevalent in patients on HD than predialysis patients. Patients on HD were about 3 folds more likely to have $\mathrm{PH}$ (odds ratio $=3, \mathrm{P}=0.02)$ (table 2). 


\section{International Journal of Science and Research (IJSR) \\ ISSN (Online): 2319-7064}

Index Copernicus Value (2015): 78.96 Impact Factor (2015): 6.391

Table 2: Distribution of PHT among studied groups

\begin{tabular}{|c|c|c|c|c|c|}
\hline \multirow{2}{*}{ Variable } & $\begin{array}{c}\text { Pre dialysis } \\
\text { Group }\end{array}$ & HD Group & \multirow{2}{*}{ OR * } \\
\cline { 2 - 4 } & No. & $\%$ & No. & $\%$ & \\
\hline Pulmonary hypertension \\
\hline Present & 5 & 12.5 & 12 & 30.0 & \multirow{2}{*}{ OR=3 } \\
\hline Absent & 35 & 87.5 & 28 & 70.0 & \\
\hline Severity of PHT \\
\hline Mild 45 mmHg & 1 & 20.0 & 1 & 8.3 \\
\cline { 1 - 4 } Moderate45 - 60 mmHg & 3 & 60.0 & 9 & 75.0 \\
\hline Severe > 60 mmHg & 1 & 20.0 & 2 & 16.7 & \\
\hline \multicolumn{5}{|c|}{ OR= odds ratio } \\
\hline
\end{tabular}

It had been found that there is correlation between pulmonary hypertension and Total anemia and also was more prevalent in anemic patients. Anemic patients were About 3.4 folds more likely to have $\mathrm{PH}, \mathrm{OR}=3.42, \mathrm{P}=0.026$ (table 3 ).

Table 3: Correlation between Anemia among patients with or without $\mathrm{PH}$

\begin{tabular}{|c|c|c|c|c|c|c|}
\hline \multirow{2}{*}{ Factor } & \multicolumn{2}{|c|}{ PH group } & \multicolumn{2}{c|}{ Non PH group } & \multicolumn{2}{|c|}{ Total } \\
\cline { 2 - 7 } & No. & $\%$ & No. & $\%$ & No. & $\%$ \\
\hline Present & 11 & 64.7 & 22 & 34.9 & 33 & 41.25 \\
\hline Absent & 6 & 35.3 & 41 & 65.1 & 47 & 58.75 \\
\hline Total & 17 & 100.0 & 63 & 100.0 & 80 & 100.0 \\
\hline \multicolumn{6}{|c|}{ OR= 3.42, $\mathbf{P = 0 . 0 2 6}$} \\
\hline
\end{tabular}

Table 4: distribution of $\mathrm{PH}$ according age

\begin{tabular}{|c|c|c|}
\hline Age groups & \multicolumn{2}{|c|}{ PHT } \\
\hline & No. & Percentage \\
\hline $\mathbf{2 0 - 3 0}$ yrs & 0 & $0 \%$ \\
\hline $\mathbf{3 0 - 4 0 ~ y r s ~}$ & 1 & $5.9 \%$ \\
\hline $\mathbf{4 0 - 5 0}$ yrs & 4 & $23.5 \%$ \\
\hline $\mathbf{5 0 - 6 0}$ yrs & 6 & $35.3 \%$ \\
\hline 60-70 yrs & 6 & $35.3 \%$ \\
\hline Total & 17 & $100 \%$ \\
\hline
\end{tabular}

Table 5: Distribution of total patient \&patients with PH according to CKD stage

\begin{tabular}{|c|c|c|c|c|}
\hline $\begin{array}{c}\text { CKD } \\
\text { stage }\end{array}$ & $\begin{array}{c}\text { Predialysis } \\
\text { group }\end{array}$ & $\begin{array}{c}\text { Hemodialysis } \\
\text { group }\end{array}$ & $\begin{array}{c}\text { PH distribution } \\
\text { according stage }\end{array}$ & Percentage \\
\hline 1 & 0 & 0 & 0 & $0 \%$ \\
\hline 2 & 12 & 0 & 1 & $1.25 \%$ \\
\hline 3 & 17 & 0 & 1 & $1.25 \%$ \\
\hline 4 & 11 & 0 & 3 & $3.75 \%$ \\
\hline 5 & 0 & 40 & 12 & $15 \%$ \\
\hline $\begin{array}{c}\text { Total } \\
\text { no. }\end{array}$ & 40 & 40 & 17 & $21.25 \%$ \\
\hline
\end{tabular}

\section{Discussion}

During the last four decades, patient with ESRD maintain life with the aid of HD by AV shunt. But the effect of this large access was not studied. In this study we looked for PAP in all CKD groups (pre HD \&with HD) after exclusion of possible causes of secondary PH other than CKD. 40 patients 50\% in our study had AV access from them 12patients (30\%)had PH which is high in comparison with common population prevalence $(5 \%)$ in older than 40 years as Olmsted County study, and primary PH 2 cases per million with strong female predominance, while in predialysis group 40patients (50\%)from total sample prevalence of PAH was 5 patients(12.5\%) which is clinically significant, so we could hypothesize that both CKD in general \& HD with AV access in specific contribute in pathogenesis of PH. In comparison between both predialysis \& HD group with AV fistula there is no significance found between both groups regarding selection of samples that give good comparison rate.

Anemia which show significant increase $\mathrm{PH}$ in anemic patients in both groups (predialysis \&HD group (table 3).So anemia is significantly more frequent in HD group and with high incidence of $\mathrm{PH}$ its percentage in total patients was $41.25 \%$ while in patients with $\mathrm{PH}$ was $64.7 \% 3.4$ folds more than normal. We find from this study great relation between $\mathrm{PH}$ and $\mathrm{HF}$ with left ventricular dysfunction and volume overload in addition to effect of anemia and AV access and that agree with study from Egypt of medium quality. While the relation between $\mathrm{PH}$ and age show significant increase in prevalence of PH with increase of age (table 4), that show $0 \%$ from affected patients in $3^{\text {rd }}$ decade gradually increase to $35.3 \%$ equally in both 6 th $\%$ 7th decades. This mean that age is important risk factor in increasing incidence of $\mathrm{PH}$ of CKD that together with $\mathrm{HF}$ with volume overload, $\mathrm{HD}$, and anemia contributing in pathogenesis of $\mathrm{PH}$ which indicated by high percentage in these groups of study. When we compare results according stages of CKD we find 17 patients with $\mathrm{PH}$ (total ) from them 12 with stage 5(ESRD)while 0 with stage 1.So PH in both groups increase in prevalence with more prevalence in HD group. Patients with PH were 17 from 80 from them 5 from predialysis and 12 from HD group from them 2 with mild $\mathrm{PH}(<45 \mathrm{mmHg}), 12$ moderate $\mathrm{PH}(45-$ $60 \mathrm{mmHg}), 3$ with severe $\mathrm{PH}(>60 \mathrm{mmHg})$, this may related to selected duration of HD (3-6months) and when duration increase this result may increase in number and severity (table 5)

\section{Conclusion}

$\mathrm{PH}$ is prevalent in patients with CKD that indicating it contributes in pathogenesis of $\mathrm{PH}$, and there is significant increase in prevalence in patients with ESRD on HD. Several risk factors including LV dysfunction, AV Fistula, anemia \&imbalance between vasoconstrictor \& vasodilator substances are implicated in PH in patients with CKD. PH has been associated with a higher risk of death in patient with CKD.

\section{Acknowledgments}

The authors acknowledge the contribution and cooperation of the patients enrolled for the study.

\section{Funding}

No funding sources.

\section{Conflict of interest}

None declared. 


\section{International Journal of Science and Research (IJSR) \\ ISSN (Online): 2319-7064}

Index Copernicus Value (2015): 78.96 Impact Factor (2015): 6.391

\section{References}

[1] Lam CS, Borlaug BA, Kane GC, Enders FT, Rodeheffer RJ, Redfield MM. Age-associated increases in pulmonary artery systolic pressure in the general population. Circulation. 2009;119:2663-2670.

[2] Simonneau G, Robbins IM, Beghetti M, et al. Updated clinical classification of pulmonary hypertension. J Am CollCardiol.2009;54(1 suppl):S43-S54

[3] Hachulla E, Gressin V, Guillevin L, et al. Early detection of pulmonary arterial hypertension in systemic sclerosis: a French nationwide prospective multicenter study. Arthritis Rheum. 2005;52:3792-3800

[4] Pabst S, Hammerstingl C, Hundt F, et al. Pulmonary hypertension in patients with chronic kidney disease on dialysis and without dialysis: results of the PEPPERStudy. PLoSOne. 2012; 7:e35310

[5] Yigla M, Fruchter O, Aharonson D, et al. Pulmonary hypertension is an independent predictor of mortality in hemodialysis patients. Kidney Int. 2009;75:969-975

[6] Ramasubbu K, Deswal A, Herdejurgen C, Aguilar D, Frost AE. A prospective echocardiographic evaluation of pulmonary hypertension in chronic hemodialysis patients in the United States: prevalence and clinical significance. Int J Gen Med.2010;3:279-286

[7] Evans AM, Hardie DG, Peers C, Mahmoud A. Hypoxic pulmonary vasoconstriction: mechanisms of oxygensensing. Curr Opin Anaesthesiol. 2011;24:13-2.

[8] Nizar A.Jasim, Ziad S. Alrawi, Ali A. Allawi. Renal involvement in 25 patients with

systemic sclerosis.IPMJ. 2009;8(1):1-6.

[9] Sakao S, Tatsumi K, Voelkel NF. Reversible or irreversible remodeling in pulmonary arterial hypertension. Am J Respir Cell MolBiol. 2010;43:629634

[10] Halpern SC, Taichman DB. Misclassification of pulmonary hypertension due to reliance on pulmonary capillary wedge pressure rather than left ventricular enddiastolic pressure. Chest. 2009;136:37-4

[11] Clarkson MR, Giblin L, Brown A, Little D, Donohoe J. Reversal of pulmonary hypertension after ligation of a brachiocephalic arteriovenousfistula. Am J Kidney Dis. 2002;40:e8

[12] Yigla M, Abassi Z, Reisner SA, Nakhoul F. Pulmonary hypertension in hemodialysis patients: an unrecognized threat.SeminDial. 2006;19:353-357.

[13]Zoccali C. The endothelium as a target in renal diseases. J Nephrol. 2007;20(12):39-44

[14] Jawad I.Rasheed, Suad B.Alwindawy, Ali A. Allawi. Arterial hypertension and its outcome in a cohort of renal transplant recipients in Iraq.2004;3(2):147-155.

[15] Giaid A, Saleh D. Reduced expression of endothelial nitric oxide synthase in the lungs of patients with pulmonary hypertension. N Engl J Med. 1995;333:214221

[16] Kielstein JT, Bode-Böger SM, Hesse G, et al. Asymmetrical dimethylarginine in idiopathic pulmonary arterial hypertension.ArteriosclerThrombVascBiol. 2005;25:1414-1418

[17]Zoccali C, Mallamaci F, Tripepi G. Nocturnal hypoxemia predicts incident cardiovascular complications in dialysis patients.J Am SocNephrol. 2002;3:729-733

[18] Ressl J, Urbanová D, Widimský J, Ostádal B, Pelouch V, ProcházkaJ. Reversibility of pulmonary hypertension and right ventricular hypertrophy induced by intermittent high altitude hypoxia in rats. Respiration. 1974;31:3846

[19] Sica AL, Greenberg HE, Ruggiero DA, Scharf SM. Chronic-intermittent hypoxia: a model of sympathetic activation in the rat. RespirPhysiol. 2000;121:173-184

[20]Barceló A, de la Peña M, Ayllón O, et al. Increased plasma levels of asymmetric dimethylarginine and soluble CD40 ligand in patients with sleep apnea. Respiration. 2009;77:85-90

[21] Grassi G, Seravalle G, Ghiadoni L, et al. Sympathetic nerve traffic and asymmetric dimethylarginine in chronic kidney disease. Clin J Am SocNephrol. 2011;6(11):2620-2627

[22] Mallamaci F, Tripepi G, Maas R, Malatino L, Böger R, Zoccali C. Analysis of the relationship between norepinephrine and asymmetric dimethyl arginine levels among patients with end-stage renal disease. J Am SocNephrol. 2004; 15:435-444

[23] Buemi M, Senatore M, Gallo GC, et al. Pulmonary hypertension and erythropoietin. Kidney Blood Press Res. 2007;30:248-252

\section{Author Profile}

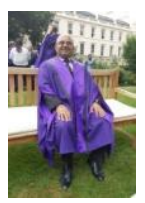

Dr. ALI A. Allawi FRCP (London), Assistant professor Baghdad College of medicine university of Baghdad. Consultant in nephrology and kidney transplantation at The Medical City Teaching Hospital Complex, The Iraqi Center for Kidney diseases and Transplant Center. Qualified with M.B.Ch.B at 1990 from College of Medicine, University of Baghdad. F.I.C.M. in Medicine (fellow of Iraqi committee of medical Specialization) since 1999. F.I.C.M. in Nephrology (Iraqi Board of Medical Specialization) since 2003.A member of kidney transplant teams at The Iraqi Center for kidney diseases and transplantation and Jenin Private Hospital. A Director of Consultants committee of nephrology and renal transplantation at The Ministry of Health since 2012 and current. Supervisor and Examiner / Arabic and Iraqi Boards of Nephrology and Internal Medicine. Several researches in nephrology and internal medicine was published. A member of the following Professional societies; (ASN) AMERICAN Society of Nephrology International Society of Nephrology (ISN ) European Renal Association -European Dialysis \&Transplant Association (ERA-EDTA). The Transplantation Society TTS Arab Society of Nephrology and Renal Transplant (ASNRT) member of Iraqi Society of Nephrology 